\title{
Reduction of distortion by using the low transformation temperature effect for high alloy steels in electron beam welding
}

\author{
F. Akyel $^{1}$ (D) S. Olschok ${ }^{1} \cdot$ U. Reisgen ${ }^{1}$
}

Received: 28 October 2019 / Accepted: 9 September 2020 / Published online: 26 September 2020

(C) The Author(s) 2020

\begin{abstract}
Residual stress and distortion of welded specimens are issues when it comes to geometrical requirements. The surrounding material prevents the dilatation associated with transformation in the area of heat input resulting in residual stress and distortion due to thermal contraction. In the past few years, low transformation temperature (LTT) material was successfully used as filler wire to reduce residual stress as well as distortion in the weld seam in arc welding processes. High alloy Fe-based filler materials with levels of chromium and nickel ensure a martensitic transformation at reduced temperatures in a low alloy base material. The LTT properties counteract the accumulation of stresses due to thermal contraction with compressive stresses that develop within the transformed region. This work used a high alloy base material in combination with a low alloy filler wire resulting in a microstructure that shows the same properties as LTT weld metals. This in situ alloying allows for an alloy composition tailored to the process. In order to provide a point of reference, comparable welds were made using conventional high alloy filler wire. As a result, the distortion and longitudinal residual stress was significantly reduced compared to welding with conventional filler wire.
\end{abstract}

Keywords Low transformation temperature (LTT) · Distortion · Electron beam welding · Dissimilar component welding · Metallurgy

\section{Introduction}

In the manufacturing of complex and highly precise parts, for example in vehicle engineering and electro-mechanics, geometrical precision is achieved using highly precise machining processes. If, however, the material is transferred into a liquid phase within the process chain, as is the case in all fusion welding processes, the required geometrical precision can often no longer be fulfilled. In order to join materials by welding, the complete fusion zone is molten and solidified [1]. The solid-liquid interface is locally restricted. Since the material is locally exposed to thermal load, an inhomogeneous temperature distribution and phase transformation of the

Recommended for publication by Commission IV - Power Beam Processes

F. Akyel

akyel@isf.rwth-aachen.de

1 RWTH Aachen University Welding and Joining Institute (ISF), Pontstr. 49, 52062 Aachen, Germany material occurs. High temperature gradients between the welded material and surrounding base material, as well as varying phase transformations along the heat-affected zone (HAZ) result in residual stresses. Distortion of the component occurs if the overall stress exceeds the yield strength of the material during cooling. A general approach for the reduction of residual stresses in welded parts is, besides cold forming (e.g., stretch forming, pressure testing, or peening), the postheat treatment of the parts, locally (autogenous stress relieving) or globally (stress relief annealing) [2, 3]. The latter is always connected with high additional costs since components must be annealed up to $12 \mathrm{~h}$ at a temperature of up to $600{ }^{\circ} \mathrm{C}$. Time- and cost-saving as well as energy-efficient approaches are the focus of current research, [4]. In order to increase the precision of welded structures in situ, e.g., during the manufacturing process, it must therefore be ensured that at any time of the cooling process the overall residual stresses stay lower than the temperature-dependent yield point. For example, this is achieved by employing a volume increase during the $\gamma-\alpha$-transformation of ferritic steels. A much stronger effect is achieved when transformation into the martensite phase occurs from the austenitic gamma phase $(\gamma)$. If 
Fig. 1 Stress development dependent on phase transformation stresses and shrinkage stresses [9]
Transversal residual stresses
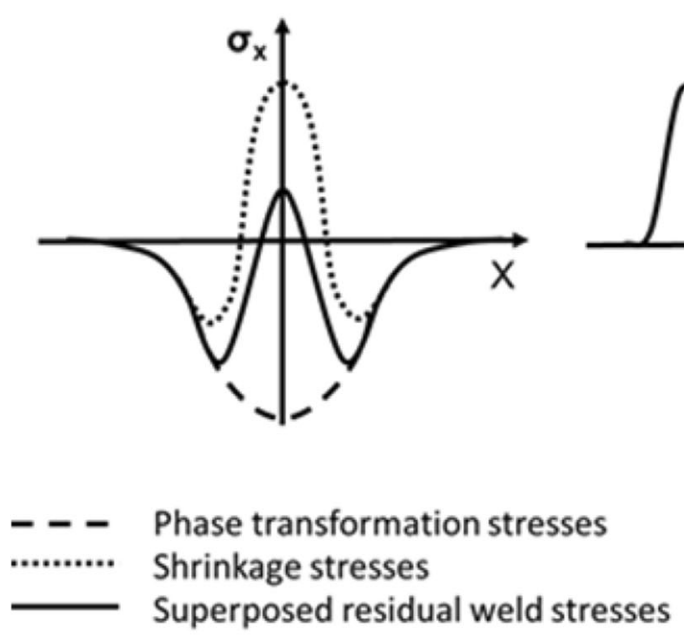

Longitudinal residual stresses
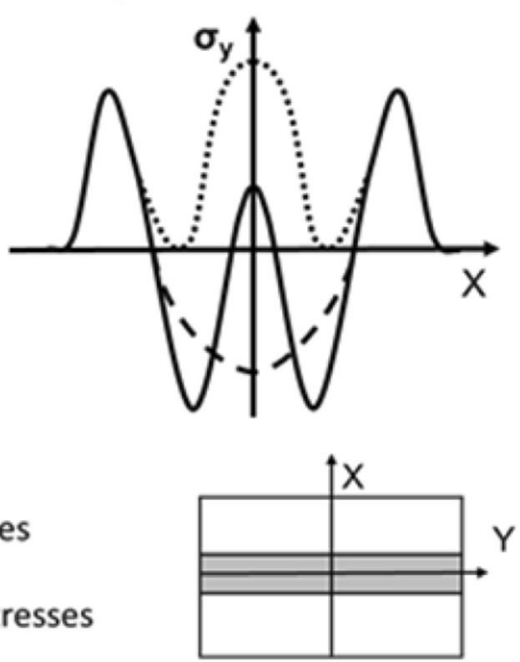

this transformation takes place at low temperatures (e.g., 200 $\left.{ }^{\circ} \mathrm{C}\right)$, i.e., if the residual stresses have already formed for a large part, it is called the low transformation temperature (LTT) effect. This paper concentrates on in situ alloying of LTT microstructure, creating the desired alloy within the welding process by control of dilution. For this, conventional material is used by combining a high alloy austenitic base material with low alloy filler wire, creating a dissimilar weld where a martensitic phase transformation can occur. In order to compare the weld and to investigate the LTT effect on the distortion and residual stress, experiments with high alloy filler wire were also carried out.

\section{State of the art}

In welded joints of steels, shrinkage and transformation residual stresses occur in the immediate weld seam area due to inhomogeneous temperature distribution and (in the case of transformable steels) phase transformation [5-7]. The exposure to local heating leads to high temperature gradients between the weld and the surrounding base material. Beginning with the cooling process the heated zone tries to shrink proportional to the maximum temperature and the thermal expansion coefficient [8]. The shrinkage is hindered by the surrounding cooler material leading to tensile residual stress within the weld seam. The higher the thermal expansion coefficient, the higher the restraint and the more residual stress build up.

Residual stress in welded specimens is a superposition of phase transformations and thermal shrinkage, Fig. 1. The profile for longitudinal stress shows a maximum in the weld seam as well as tensile residual stress peaks in the base material. Those peaks are interpreted as an equilibrium reaction caused by the phase transformation in the weld seam and the HAZ.
The residual stress, however, cannot exceed the yield strength. In a single layer weld, the longitudinal residual stress will be higher than the transverse residual stress. The latter will reach approximately $1 / 3$ of the longitudinal values [8]. While thermal shrinkage produces tensile strength along the weld seam (dotted line), phase transformations result in compressive stress in this area (dashed line). Both phenomena superpose to a resulting profile of the residual stresses, [9].

Bühler and Scheil [10] conducted experiments using ironbased materials with varying nickel contents. The residual stress was explained as a result of two competing processes: restricted shrinkage and phase transformations. The investigations showed that the martensite start temperature $\left(M_{S}\right)$ has a significant influence on the resulting residual stress formation in steels and were confirmed by Jones and Alberry [11]. The advantage of the martensite formation is that the transformation can be achieved by alloying elements while high carbon contents can be avoided. Also, the largest stress reduction can

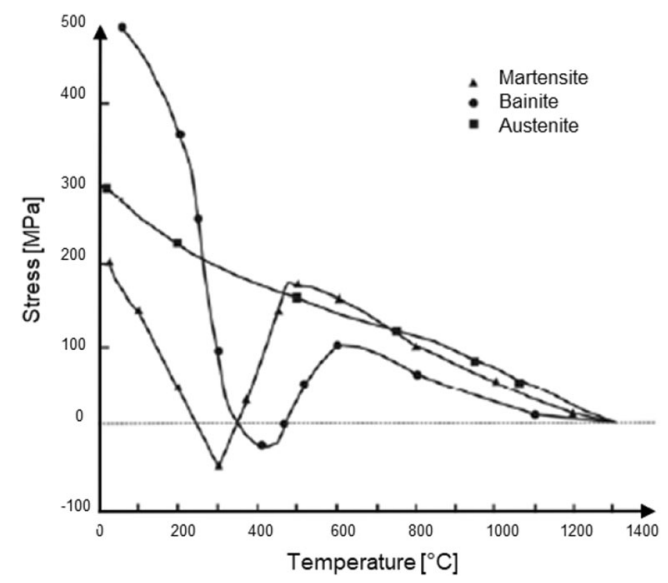

Fig. 2 Reaction stress of a fixed austenitic, bainitic, and martensitic steel during cooling [11] 


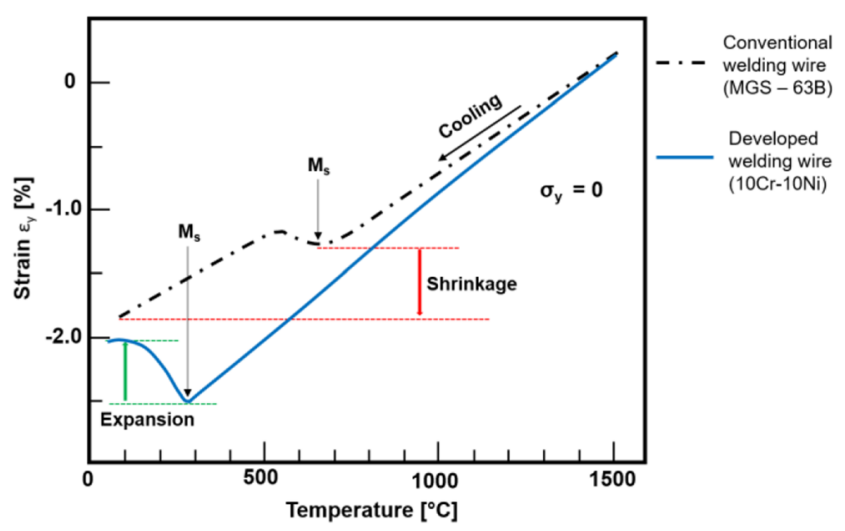

Fig. 3 Development of strain depending on martensite start temperature $M_{S}[25]$

be achieved from martensite (in comparison to ferrite and bainite) because of the high transformation strain [12].

In austenitic steels, an almost linear increase in reaction stresses with decreasing temperatures is detected, Fig. 2. As soon as a phase transformation occurs, the stress drops and extends into the compressive stress range. Afterwards, the stress builds up again whereby the rise is steeper than with purely austenite. Nevertheless, with a martensitic transformation the lowest value of the stress is achieved, as it shows a lower transformation temperature than the transformation temperature of bainite. Volume expansion by phase transformations is greater at low temperatures because the thermal expansion is greater when austenite transforms to ferrite in the cooling phase than when ferrite transforms to austenite in the heating phase, $[13,14]$.

The LTT effect is used in order to control the weld residual stresses by adjustment of the martensite phase transformation during the welding process [12]. Most investigations reduce $M_{S}$ by control of the alloying elements chromium and nickel. Investigations are also present, where the nickel and manganese composition [15] or only the nickel composition [16] is varied. With the research of Ohta et al. [17], the first residual stress measurement on LTT welds were analyzed. They showed that tensile residual stresses at the weld toe could be reduced when using an LTT alloy with a $M_{S}$ of $180{ }^{\circ} \mathrm{C}$. Further research of [18] and [19] could prove that compressive stresses generate even with varying $M_{S}$. Those results were supported by different authors as well [20-22]. In [23] and [24], an increase in compressive stress especially in longitudinal direction could be achieved, when the interpass temperature is close to $M_{S}$ of the LTT welds.

There is no proper definition for the composition of an LTT material. In general, $10 \mathrm{wt} \% \mathrm{Cr}$ and $10 \mathrm{wt} \% \mathrm{Ni}$ are taken as a guideline, whereas the actual target is to reduce the $M_{S}$ temperature to the range that is needed. In low alloy steels, the martensite start temperature is around $500{ }^{\circ} \mathrm{C}$. The volume shrinks when reaching room temperature and the martensite finish temperature $M_{f}$ is reached. Reducing $M_{S}$ to lower temperatures at around $200{ }^{\circ} \mathrm{C}$ results in a volume expansion while reaching room temperature (Fig. 3). If, however, $M_{S}$ is reduced too much, martensite formation will not be completed since $M_{f}$ drops below room temperature and shrinkage will occur again. Therefore, it is to take into account, that $M_{S}$ is not reduced too much [25].

Most researches show that the effect can be used for arc welding processes. The development of residual stress is not dependent on the size of a weld but rather of the ratio between heated and cold areas or, in the case of phase transformations, the ratio between transforming and non-transforming areas. This means that the grade of restraint in a small beam welded part can be higher than in a thick walled construction that was subjected to the high heat input of arc welding [8]. In beam welding, the heat input depends on beam power and weld speed, affecting the cooling velocity and the ratio between heated zone and cold material. The control of it, however, is not easy to handle especially with regard to the residual stress. Thus, thermal distortion cannot be influenced without further ado; however, the influence of phase transformation can be influenced by means of targeted alloying in order to build up further compressive stresses in the weld seam. The higher the banitic or martensitic content in the microstructure, the more the residual stress dependents on the transformation temperature [8]. In order to use the LTT effect in beam welding, investigations were carried out by Francis et al. [26] and Gach et al. [27]. Here, a comparison of conventional filler material and LTT filler material in carbon manganese steel was conducted. The results showed that the LTT influences the temperature profile by changing the weld pool shape. Digital image correlation
Table 1 Chemical composition of the used material in wt\% (not all elements are listed)

\begin{tabular}{|c|c|c|c|c|c|c|c|c|c|}
\hline \multirow[t]{2}{*}{ Material } & \multicolumn{9}{|c|}{ Main alloying additions in filler wire (wt $\%$ ) } \\
\hline & $\mathrm{Fe}$ & $\mathrm{C}$ & $\mathrm{Si}$ & Mn & $\mathrm{Cr}$ & $\mathrm{Ni}$ & Mo & $\mathrm{P}$ & $\mathrm{S}$ \\
\hline \multicolumn{10}{|l|}{ Base material } \\
\hline $1.4301 / 304$ & 70.5 & 0.03 & 0.43 & 1.57 & 18.4 & 7.86 & 0.3 & 0.03 & $<0.001$ \\
\hline \multicolumn{10}{|c|}{ High alloy filler wire (similar weld) } \\
\hline G19 9/308L & 67.6 & 0.02 & 0.76 & 1.61 & 19.61 & 9.68 & 0.17 & 0.02 & 0.01 \\
\hline \multicolumn{10}{|c|}{ Low alloy filler wire (dissimilar weld) } \\
\hline G3Si1/70S-6 & 97.4 & 0.09 & 0.09 & 1.35 & 0.02 & 0.02 & $<0.005$ & 0.01 & 0.02 \\
\hline
\end{tabular}


Fig. 4 Experimental setup, left: miniDrive filler wire system, right: schematic illustration of the welding trials with filler wire
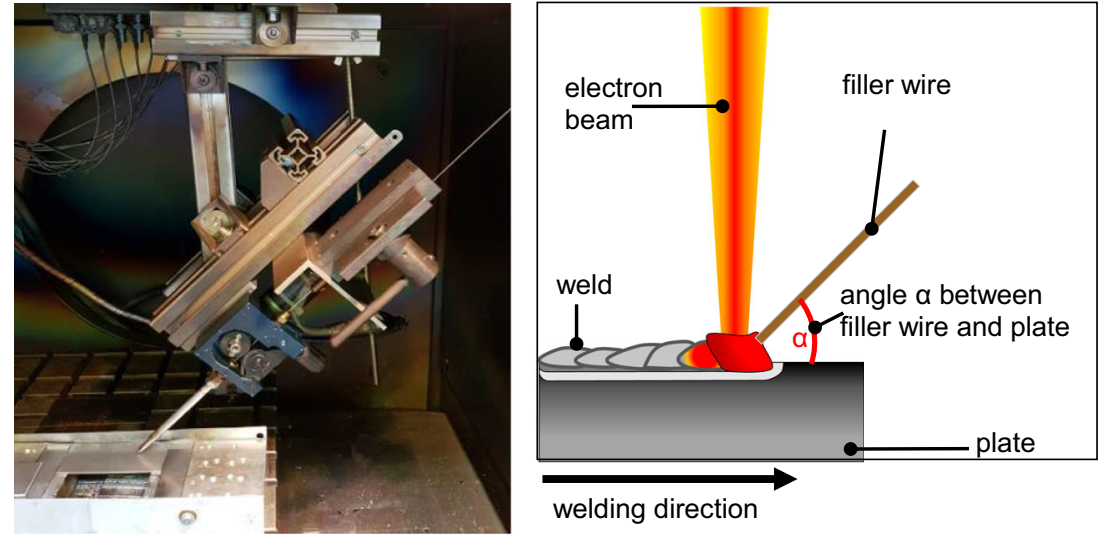

diagnostics showed the reduced displacement on the surface with LTT filler wire compared to conventional filler wire, proving that the LTT effect can also be used in beam welding.

In literature, many formulae exist to describe the relationship of $M_{S}$ with the alloying elements, [28-33]. These formulae can be used in a limited alloying range or for a specific material group. In [34], different formulae were investigated with respect to the prediction of $M_{S}$ temperatures for both low and high alloy steels. It was found that the lowest scatters between measured and calculated $M_{S}$ in low and high alloy materials were achieved with the formulae of Steven and Haynes [29] and Andrews [28]. Steven and Haynes turned out to be more robust for high chromium contents. As in this work high $\mathrm{Cr}$ content is present, the equation according to Steven and Haynes is used, Eq. 1.

$\mathrm{M}_{\mathrm{S}}=561-474 \mathrm{C}-33 \mathrm{Mn}-17 \mathrm{Cr}-17 \mathrm{Ni}-21 \mathrm{Mo}\left[{ }^{\circ} \mathrm{C}\right]$

\section{Welding experiments}

\subsection{Material}

A high alloy austenitic steel sheet 1.4301 (X5CrNi 18-10/ AISI 304) with the dimensions of $100 \times 50 \times 2 \mathrm{~mm}$ was welded lengthwise with filler wire in a single pass. Two different filler wires were used but no seam preparation (bead on plate with free root formation). A high alloy filler wire G19 9 (EN ISO 14343-A G19 9 L Si/ AWS A5.9:ER308LSi) and a low alloy filler wire G3Si1 (EN ISO 14341-A:G 383 C1 3Si1/ AWS A5.18:ER70S-6) both by the company ESAB, Sweden, and both with a $1 \mathrm{~mm}$ diameter were used during the welding trials.

The chemical composition of the materials was measured using an optical emission spectrometer (OES) (Table 1). To be able to measure the thin filler wires, they were melted in ceramic crucibles into larger samples.

\subsection{Experimental setup}

Welding trials were carried out on an electron beam welding machine pro-beam K7 with an acceleration voltage of $120 \mathrm{kV}$. For all trials, a beam current of $7 \mathrm{~mA}$, a welding speed $v_{w}=$ $0.54 \mathrm{~m} / \mathrm{min}$ and a wire feed rate $v_{f}=0.5 \mathrm{~m} / \mathrm{min}$ were used. The inclination angle of the filler wire was $45^{\circ}$, the miniDrive feeding wire system, developed by the Welding and Joining Institute of RWTH Aachen University, was used (Fig. 4). At least 5 welds of each material combination were carried out. The specimen was not clamped in order to ensure free thermal expansion or distortion.

Welding trials were made with the high alloy base material and two different filler wires; the low alloy

Fig. 5 Cross section of dissimilar composition weld, base material 1.4301/304 welded with G3Si1/ 70S-6 filler wire, a macro section of the weld, $\mathbf{b}$ micro section of the weld seam showing the transition zone between upper and lower weld seam area
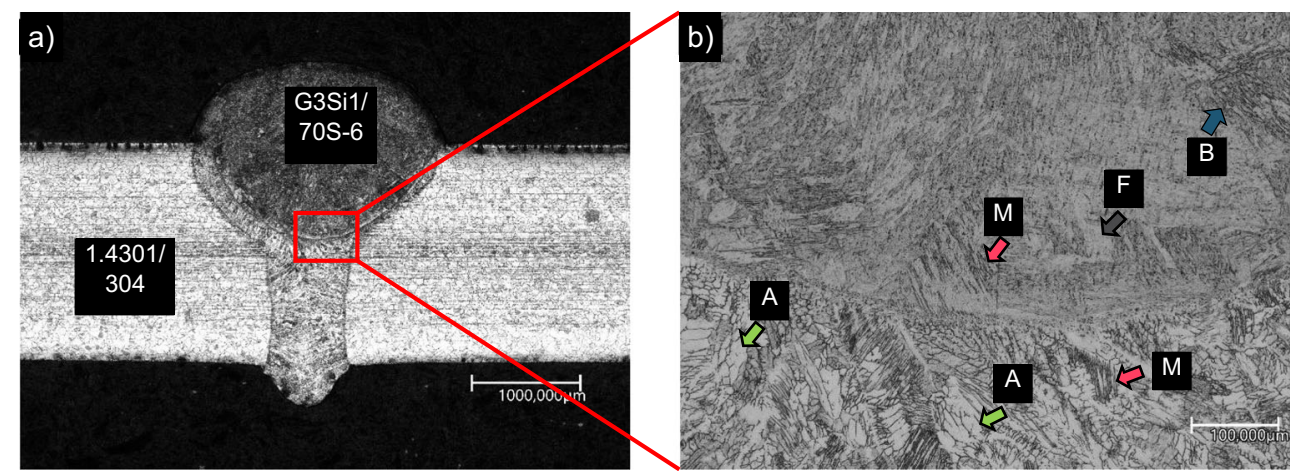
Fig. 6 Color etching of the dissimilar composition weld with Beraha II etchant, a macroscopic image of the weld seam, $\mathbf{b}$ transition zone between upper and lower weld seam, $\mathbf{c}$ transition zone between upper weld seam and base material, $\mathbf{d}$ lower weld seam
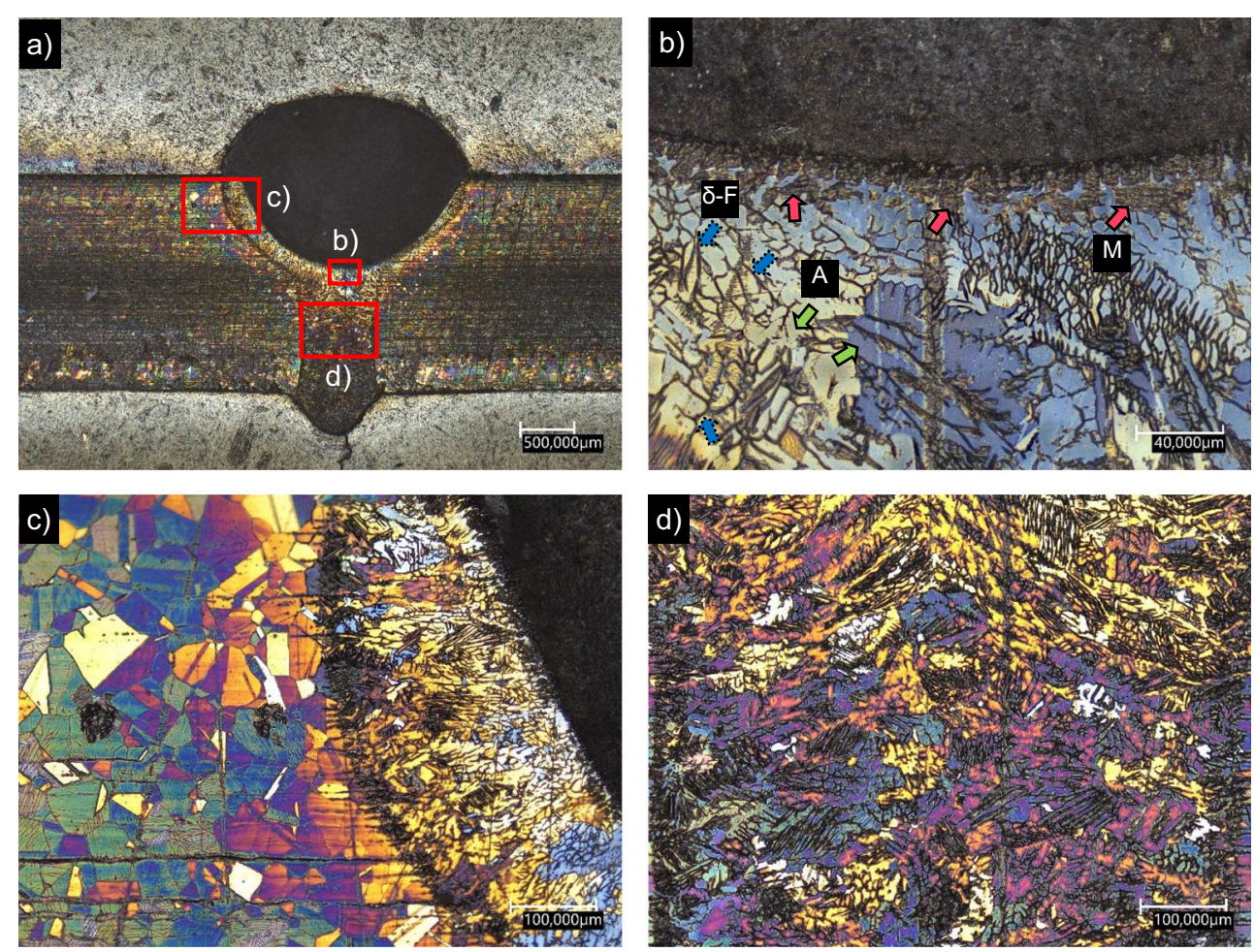

filler wire G3Si1/ 70S-6 was used to create a LTT microstructure (dissimilar composition weld), whereas the high alloy filler wire G19 9/308L was used to compare the results with common weld compositions (similar composition weld).

Fig. 7 Color etching of the dissimilar composition weld with Beraha I etchant, a macroscopic image of the weld seam, $\mathbf{b}$ transition zone between upper and lower weld seam, $\mathbf{c}$ transition zone between upper weld seam and base material, $\mathbf{d}$ upper weld seam
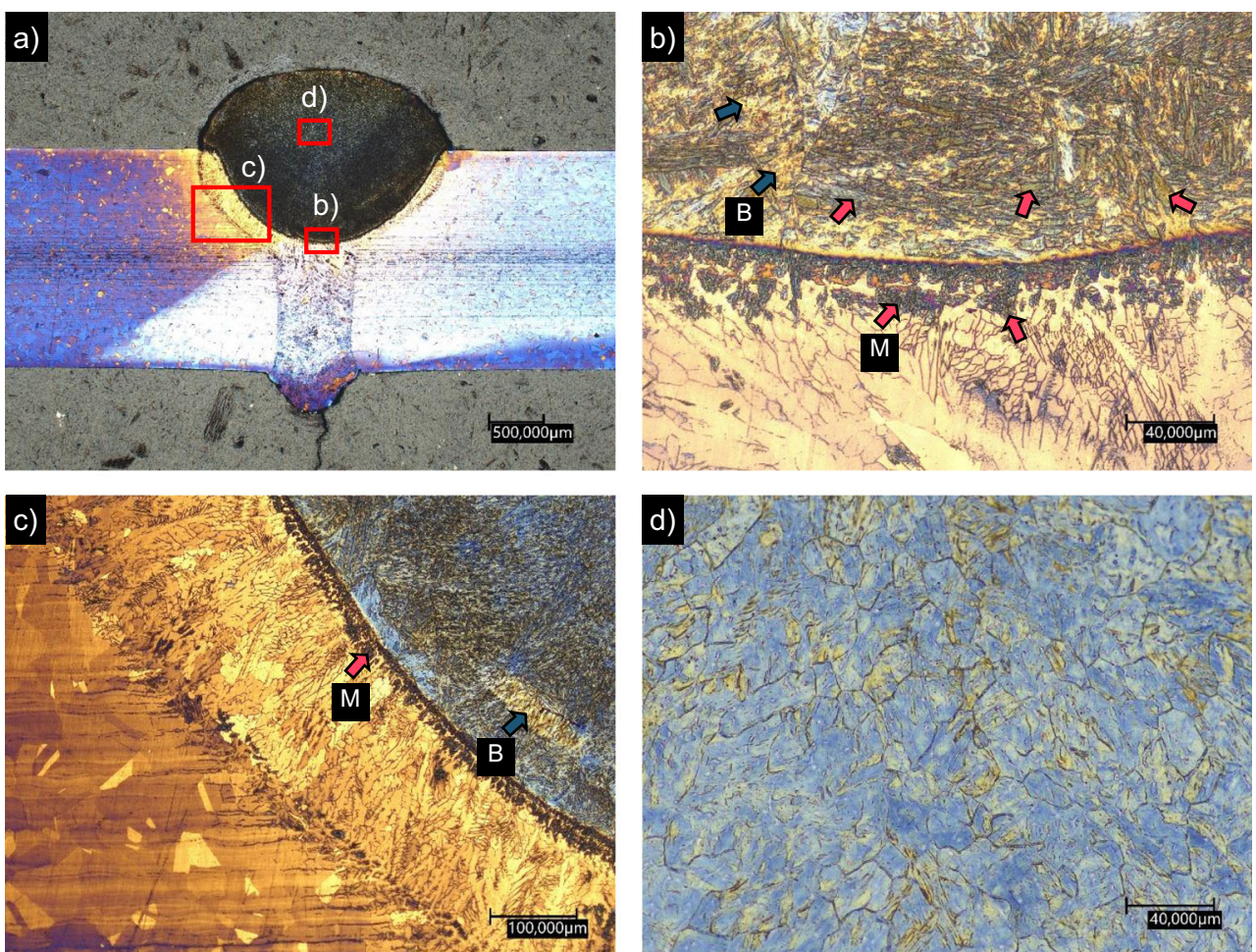
Fig. 8 Cross section of similar composition weld, base material 1.4301/304 welded with G19 9/ 308L filler wire, a macro section of the weld, $\mathbf{b}$ micro section of the weld seam

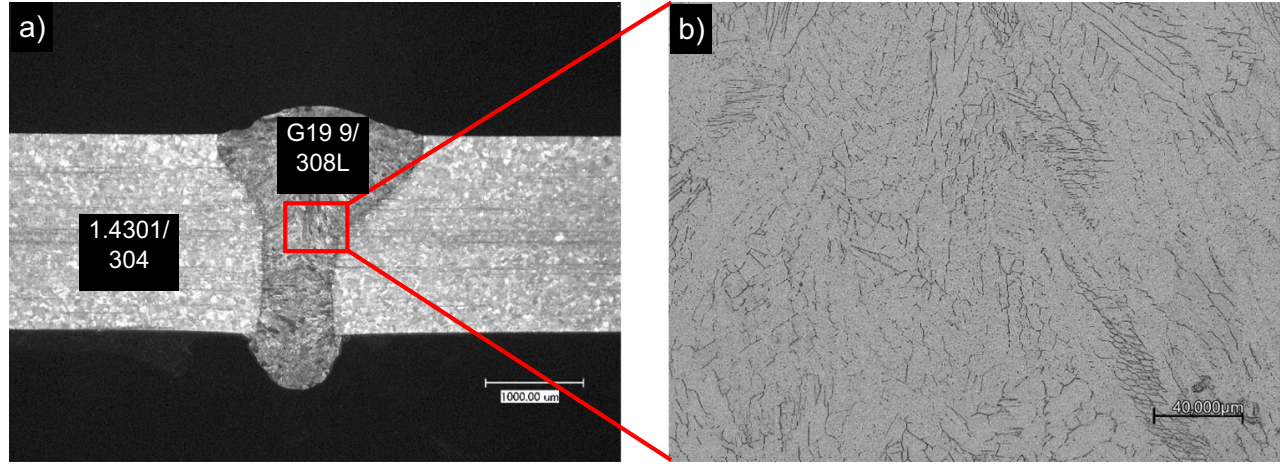

behavior, especially during dissimilar composition welding. First the dissimilar composition weld was analyzed (Fig. 5). Because of the austenitic base material V2A etchant was used to highlight the microstructure. Commonly, this etching method is used for $\mathrm{Cr}-\mathrm{Ni}$ steel for $10-30 \mathrm{~s}$ in a temperature between 50 and $70{ }^{\circ} \mathrm{C}$.

When looking at the macro section, it is noticeable that a distinction can be made between the upper and lower weld seam area. Macroscopically, the low alloy wire material does not appear to have been completely mixed with the high alloy base material (Fig. 5-a).

The carbon content determines the appearance of martensite. At carbon contents $<0.5 \%$, lath martensite is formed [35]. When examining the micro section of the upper weld seam area, martensitic, ferritic, and bainitic microstructures were detected (Fig. 5-b). Bainitic microstructures are typical for alloyed steels, since the diffusion processes of the alloying elements are greatly delayed [36]. This contributes to the formation of microstructures that take a longer time to form. When welding high alloy materials, defects in form of solidification cracks can often occur. No cracks, however, were found during examining the cross sections.

To further differentiate the present microstructure, color etching is applied to the samples. First, the sample is etched with Beraha II etchant. This color etchant is a cold etching

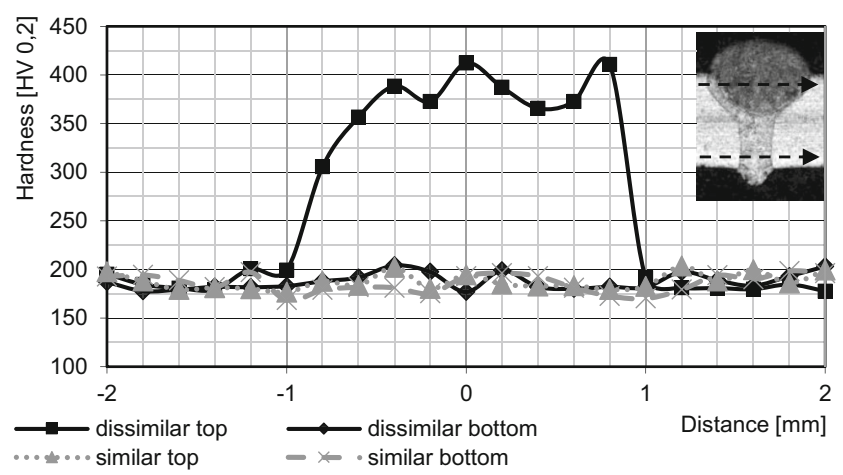

Fig. 9 Comparison of hardness values in the top and bottom parts of dissimilar and similar composition welds method and typically used for austenitic $\mathrm{Cr}-\mathrm{Ni}$ steels to especially highlight austenite (Fig. 6).

It is important to note that the colors do not give a definitive statement about the existing phase, but serve as an additional aid for interpretation. During etching, ferrite is etched first because of its low carbon content. For this reason, areas with low alloying elements or high ferrite content appear dark to almost black. In contrast, areas with high alloying elements or chromium carbides, for example, appear almost white. First, the complete weld seam is observed macroscopically (Fig. 6a). The upper part of the weld is dark while the rest of the weld and the base material are shown in different colors. This shows that the alloying elements within the upper weld area are lower compared to the bottom area. In the transition area between the upper and lower area of the weld martensite is detected (Fig. 6-b). The blue or yellowish areas indicate austenite. Dark lines between the austenite indicate $\delta$-ferrite. Next, the transition zone between the upper weld seam and the base material is examined (Fig. 6-c). In the base material, the martensitic microstructure with a low proportion of dark delta ferrite lines can be seen. In the area close to the dissimilar weld zone, the $\delta$-ferrite content increases significantly. Finally, the lower area of the weld seam is observed (Fig. 6d). Here as well, yellow areas show the presence of austenite. The white zones could be the presence of chromium carbides. The darker (purple) zones around the white carbides indicate lower alloying elements, which suggest carbide depletion.

With Beraha II etching, the microstructure of the upper weld seam could not be identified. For this reason, the sample is prepared with a Beraha I etching as well. This cold etching method is suitable for low alloy steels and is particularly useful for the visualization of martensite (Fig. 7).

Beraha I etchant visualizes the microstructure in the upper area of the weld seam (Fig. 7-a). Here, also a martensite seam can be detected at the boundary between the upper and lower weld seam (Fig. 7-b). This is a typical phenomenon when joining high and low alloy materials. Martensite is shown as brown-blue areas while bainite is shown as yellowish areas. In Fig. 7-c, it becomes clear that the martensite seam runs along the complete upper weld seam boundary. When observing the 
Fig. 10 Horizontal EDS line scan of a dissimilar composition welded specimen

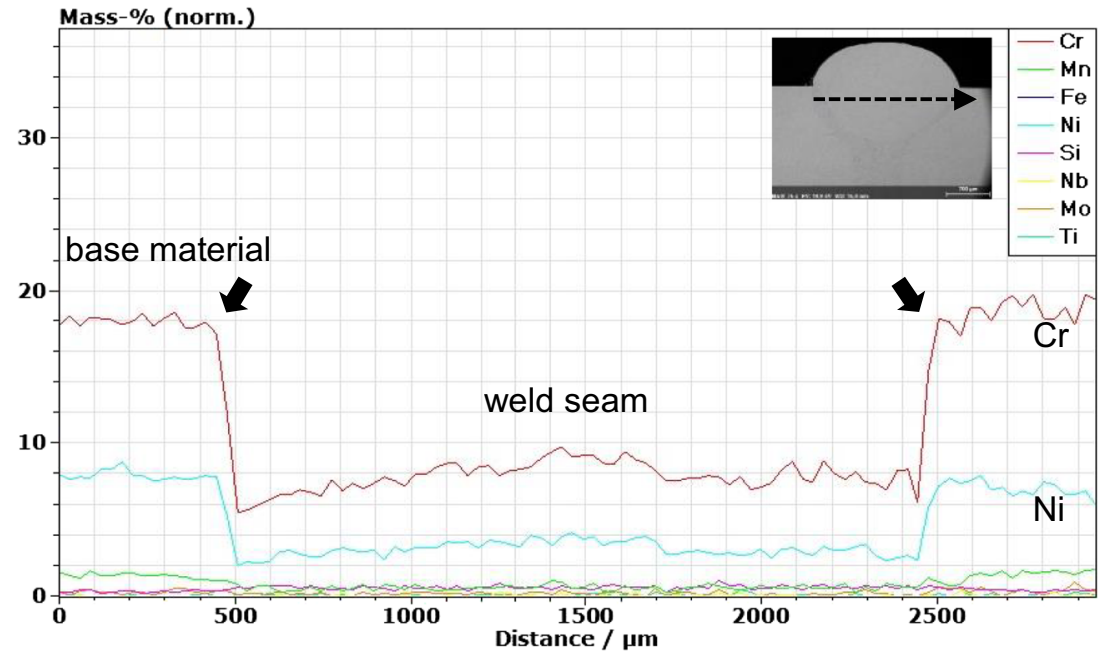

microstructure of the upper weld seam, martensite is shown in brown and blue (Fig. 7-d). Undissolved carbides are shown as small dark spots. Zones with retained austenite should become visible as white spots within the upper weld seam. When examined closely, no retained austenite could be detected.

Overall, it appears that the filler wire has not been completely intermixed with the base material. The inhomogeneous distribution of alloying elements could indicate low weld pool fluctuations. This results in a microstructure consisting of martensite and bainite in the upper area, whereas a predominantly austenitic microstructure in the lower area of the weld seam is present. In order to mix the two materials and create a higher weld pool fluctuation, beam oscillation would be necessary.

The next step was to examine the similar composition welded specimen (Fig. 8). In contrast to the dissimilar composition weld, an austenitic microstructure with dark $\delta$-ferrite lines is visible within the weld seam. Here, as well, no defects such as solidification cracks were found.

\subsection{Hardness}

After examination of the microstructure, the hardness of the welded samples was measured for further investigation. Here, hardness values were taken from the upper and lower half of the weld seam, both for the similar composition welded specimen and for the dissimilar welded specimen. The distance to the top and bottom was $0.5 \mathrm{~mm}$ each.

As expected, the hardness values for the similar composition weld were comparable with the hardness in the base material both in the upper and lower area of the weld seam. However, a clear discrepancy could be observed between the measured hardness values in the upper and lower part of the dissimilar composition weld (Fig. 9). Since the used high alloy materials cannot be hardened by heat input, there is no hardening within the HAZ or similar weld seam. Phase transformations take place solely in the upper weld seam of the dissimilar weld, which is why only in this area a hardness increase is noted. The hardness results of the dissimilar
Fig. 11 Vertical EDS line scan of a dissimilar composition welded specimen

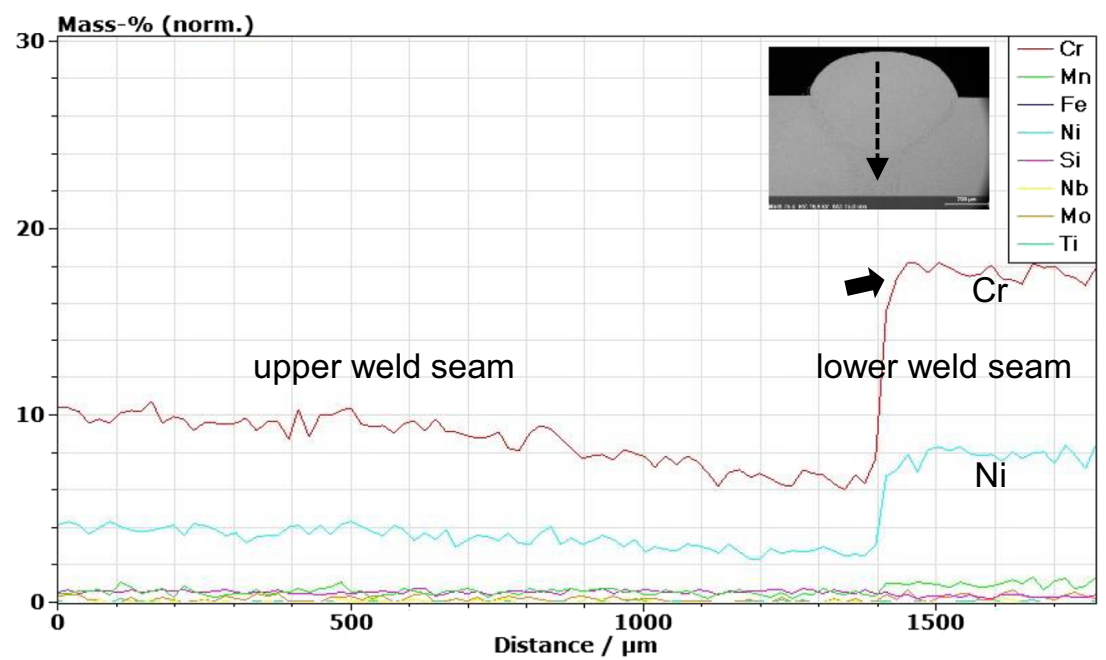


Fig. 12 Calculated progression of $M_{S}$ within the weld seam depending on the alloying elements measured in horizontal line scan

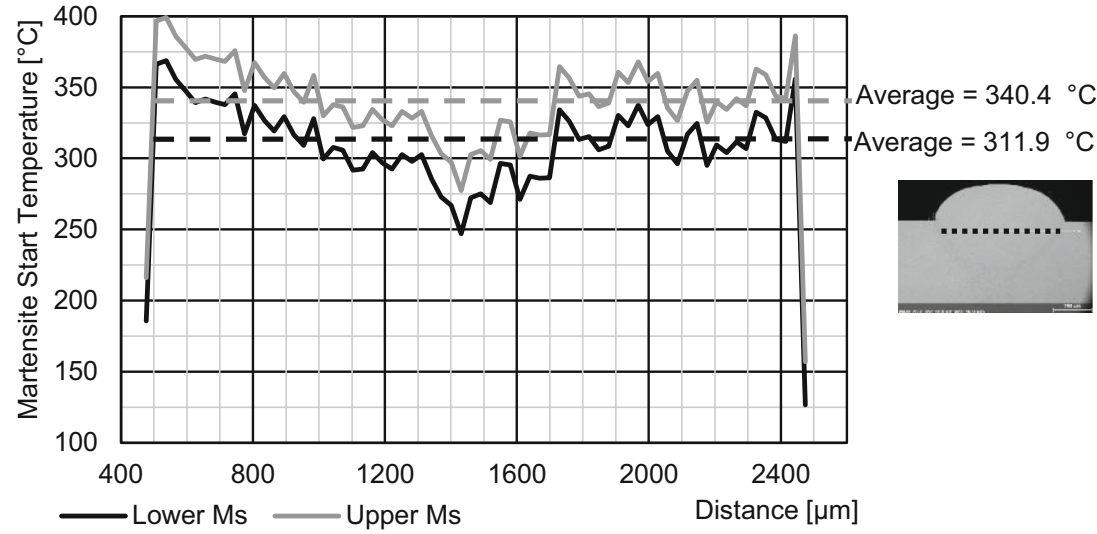

composition weld were consistent with findings from the microstructure examination. The increased hardness proved again the presence of harder structures such as martensite in the upper weld, while in the bottom austenite predominated and no increase in hardness was detected.

\subsection{EDS and martensite start temperature}

To investigate the alloying elements in the welded specimens, energy dispersive X-ray spectroscopy (EDS) was carried out. Since the similar composition weld does not have any significant change in alloying content of the weld seam, only the dissimilar composition welded specimen was analyzed. To analyze the change of alloying elements compared to the base material, a line scan horizontal through the upper weld seam was measured (Fig. 10).

It can be observed that in the transition from base material to weld seam, the decrease in chromium and nickel content is not gradually, but abrupt. Within the weld seam, the $\mathrm{Cr}$ content, for example, does not remain constant at around $6 \mathrm{wt} \%$, but increases slightly towards the middle to just under $10 \mathrm{wt} \%$.
Since the $M_{S}$ is decreased further with higher proportions of alloying elements, it reaches lower values in the middle of the weld seam compared to the area of the fusion line.

Further EDS measurements were also taken within the weld seam in the vertical direction (Fig. 11). The alloy components in the direction of specimen thickness were investigated.

In the direction of the specimen thickness (from top to root), the Cr content, among other alloy elements, decreases continuously until the transition to the higher alloyed area of the weld seam (no intermixing with the filler wire) is reached.

To calculate $M_{S}$, the carbon content of the material must be known. Since the C-content cannot be determined reliably in an EDS measurement, an upper and lower limit had to be assumed. The $\mathrm{C}$-content of the base material and the low alloy filler wire were taken as upper and lower limits. In the following, the progression of $M_{S}$ within the weld seam was calculated, using the alloying element contents measured from the horizontal line scan (Fig. 12).

The austenitic steel 304 does not have a martensitic phase transformation due to the high $\mathrm{Cr}$ and $\mathrm{Ni}$ contents. For this
Fig. 13 Measurements of angular distortion on 3D measured specimens of similar and dissimilar composition welds

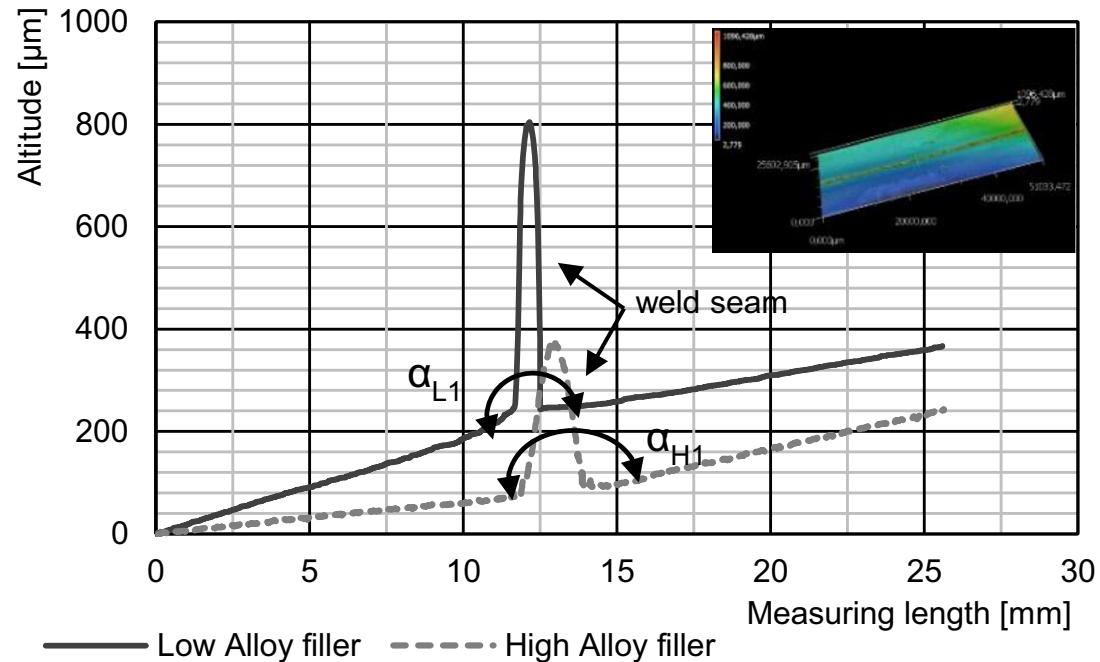




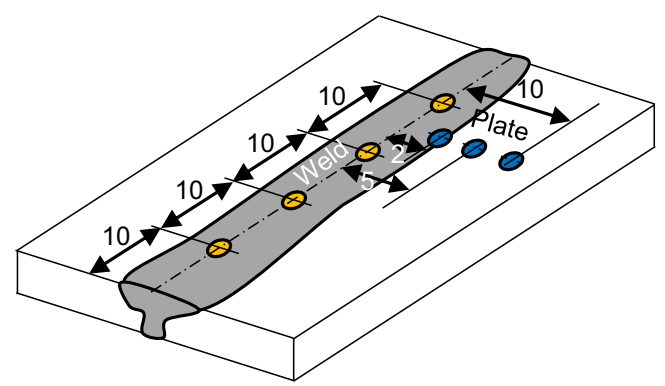

Fig. 14 Sketch of a sample measured with drill hole method along the weld seam and plate

reason, Eq. 1 is only used to calculate the $M_{S}$ temperature for the upper part of the weld seam and the base material is not included. The inhomogeneous distribution of the alloying elements led to varying $M_{S}$ within the weld seam area. In the middle area lower $M_{S}$ was calculated than in the outer area. Using the equation of Steven and Haynes the average upper limit of $M_{S}$ was calculated as around $340.4^{\circ} \mathrm{C}$ and the average lower limit of $\mathrm{M}_{\mathrm{S}}$ as around $311.9^{\circ} \mathrm{C}$. With a low carbon content, the distance between $M_{S}$ and $M_{f}$ temperature is not very high. Since the $M_{S}$ temperature was in average above 300 ${ }^{\circ} \mathrm{C}$, it can be assumed that the $M_{f}$ is reached at room temperature.

\subsection{Angular distortion}

Measurements of the angular distortion were carried out using the confocal 3D laser scanning microscope Keyence VKX1000. With this, a 3D-scan of the surface can be measured to determine the angle of distortion ex situ. A field of $25 \mathrm{~mm}$ width and $50 \mathrm{~mm}$ length was scanned and at least 4 measuring lines were recorded perpendicular to the weld seam (Fig. 13). The average of all measurements were taken and the measured angle difference to $180^{\circ}$ was calculated. This resulted in angle differences that showed whether the samples had contracted or even bent in a negative direction.

As was to be expected, the similar composition weld specimens contracted, resulting in an average distortion angle of $\alpha_{H}=\alpha_{H 1}-180^{\circ}=0.55^{\circ}$. In contrast, the dissimilar composition weld specimens even showed a bend in negative direction, with an average distortion angle of $\alpha_{L}=\alpha_{L 1}-180^{\circ}=-$ $0.08^{\circ}$. This shows that with the in situ alloying the LTT effect can be used to reduce the distortion in a high alloy base material. With the proportion of LTT structure in the upper area of the weld seam, sufficient compressive stress could be introduced into the specimen by volume expansion, so that compensation of the distortion could take place. In this case even overcompensation was achieved.
Fig. 15 Transverse residual stresses measured with drill hole method along the weld seam and plate

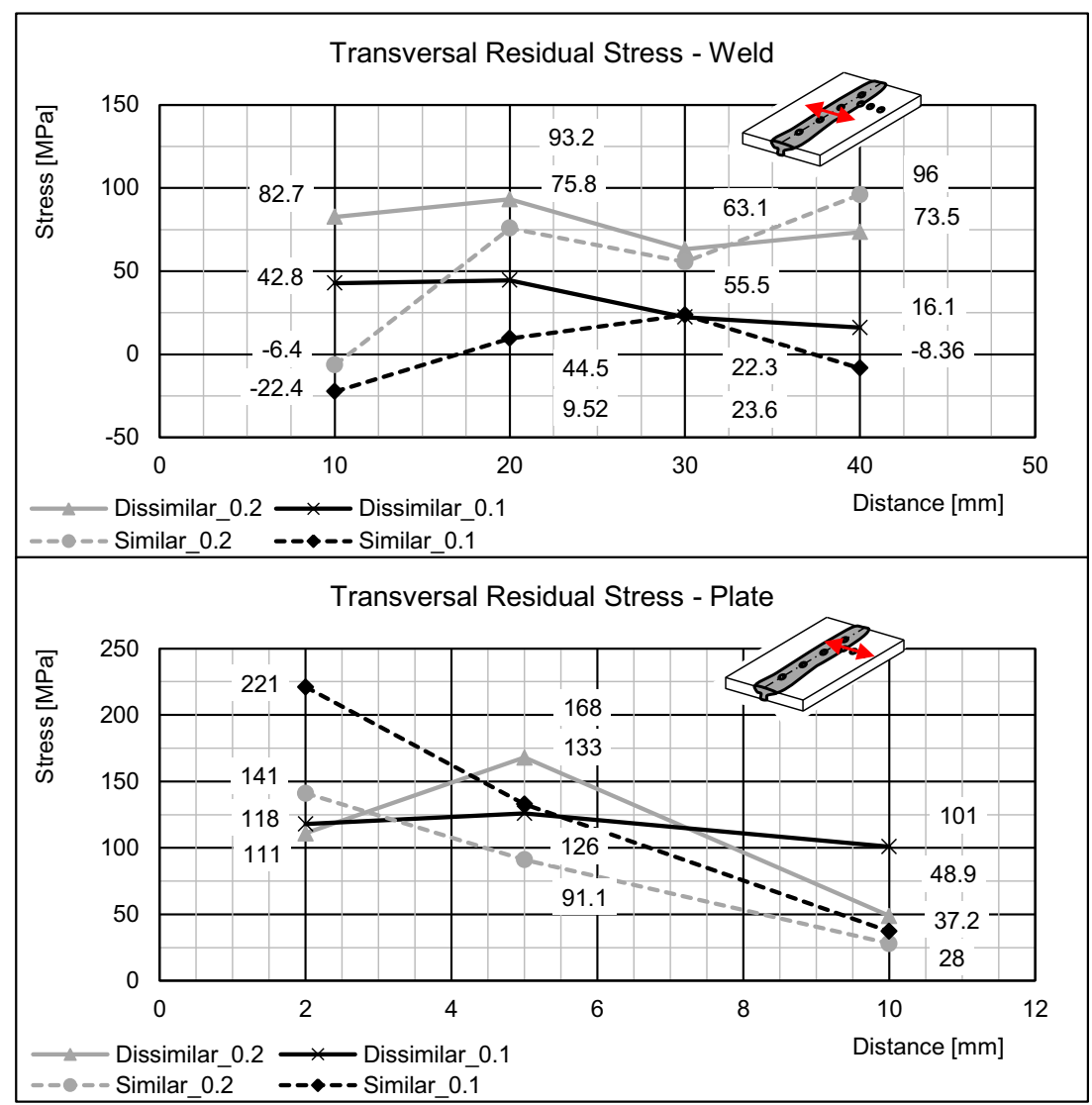




\subsection{Residual stress}

Residual stress investigations were carried out using the drill hole method. A drill with a diameter of $0.8 \mathrm{~mm}$ was used. Drilling was carried out at depths of $0.1 \mathrm{~mm}$ and $0.2 \mathrm{~mm}$. Transverse and longitudinal residual stresses were recorded. Four measuring points were carried out on the center of the weld with a distance of $10 \mathrm{~mm}$ each. Another three measuring points were carried out perpendicular to the weld seam in the direction of the base material. The distances were $2 \mathrm{~mm}, 5$ $\mathrm{mm}$, and $10 \mathrm{~mm}$ from the center of the weld (Fig. 14).

First, the transverse residual stresses are measured (Fig. $15)$. Within the weld seam, the stress values are mostly in tensile stress range. The similar weld ranges from compressive stress of about - $22 \mathrm{MPa}$ to a tensile stress of about $96 \mathrm{MPa}$ at measurement depths of 0.1 and $0.2 \mathrm{~mm}$. In the dissimilar weld, the stress values at both measuring depths are in a range of a minimum of about $16 \mathrm{MPa}$ and a maximum of over 93 MPa.

The values of transverse residual stresses within the plate are all tensile stresses. The highest stress is at the beginning of the similar weld at $0.1 \mathrm{~mm}$ depth. Here, the stress reaches values up to about $220 \mathrm{MPa}$ and drop to about $37 \mathrm{MPa}$ at a greater distance to the weld seam. In the case of dissimilar welds at $0.2 \mathrm{~mm}$ measuring depth, the values reach between a maximum of $170 \mathrm{MPa}$ and a minimum of $50 \mathrm{MPa}$. It is noticeable that the similar welds show higher tensile stress values close to the weld seam than the dissimilar weld. This reverses with a greater distance to the weld seam. Overall, the decrease in stress is greater for similar welds, where especially at $0.1 \mathrm{~mm}$ depth the tensile stress drops by a factor of nearly 6 .

Finally, longitudinal stresses are measured (Fig. 16). With the stresses in the weld seam, a clear distinction can be seen between similar and dissimilar weld. At a measuring depth of $0.1 \mathrm{~mm}$ in the similar weld, residual stresses are partly in the compression stress range. Here, the values are between $80 \mathrm{MPa}$ and a maximum of $137 \mathrm{MPa}$. In dissimilar welds, on the other hand, compressive stresses are present at the same depth. Values range between -67 and $-183 \mathrm{MPa}$. Comparable results can be seen at measuring depths of 0.2 $\mathrm{mm}$. In the similar weld, residual stresses are clearly in the tensile stress range. Values are approximately between 172 and $305 \mathrm{MPa}$. In the dissimilar weld, on the other hand, compressive stresses are present at $0.2 \mathrm{~mm}$ measuring depth. The values vary between -7 and $-60 \mathrm{MPa}$.

The longitudinal stresses within the plate have tensile stresses both in the similar and the dissimilar weld at all measuring depths. It is noticeable that here, too, the tensile stresses of similar welds are higher in the close vicinity of the weld. The highest stress values reaches $514 \mathrm{MPa}$ at $0.1 \mathrm{~mm}$ measuring depth and drops to $13.5 \mathrm{MPa}$ with greater distance to the weld seam. With a greater distance from the weld, the
Fig. 16 Longitudinal residual stresses measured with drill hole method along the weld seam and plate

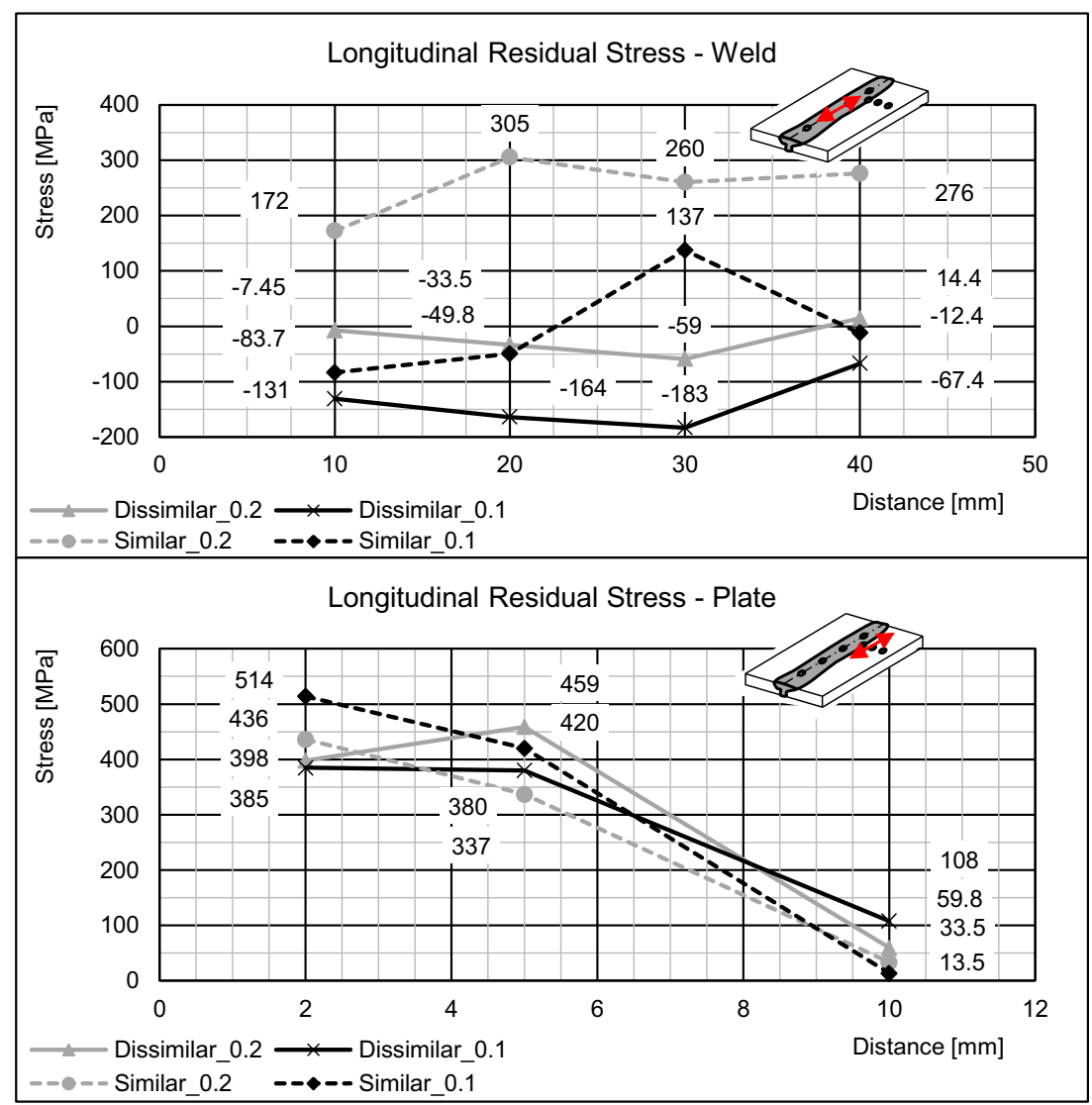


stresses of similar welds reach comparable values to the dissimilar weld.

Overall, the magnitude of longitudinal residual stresses is greater than those of transverse residual stresses. This is in agreement with research in literature. For a single layer weld without temperature gradients in thickness direction the transverse residual stresses will reach values of $1 / 3$ of the longitudinal stress [8]. The dissimilar material combination has an influence on the residual stresses within the weld seam. This influence can still be seen to a certain extent in the vicinity of the weld seam, but it does not seem to have any influence with further distance to the weld. This is attributed to the fact that the base material is a steel without phase transformations. Here, the residual stress development is based on inhomogeneous thermal distribution only.

The longitudinal residual stresses in the dissimilar weld seam at $0.2 \mathrm{~mm}$ depth show reduced compressive stresses compared to the stresses at $0.1 \mathrm{~mm}$ depth. This can be attributed to the chemical composition within the weld being inhomogeneous, resulting in inhomogeneous transformation temperatures. With the vertical line scan on Fig. 11, it can be seen that the chemical composition in the upper boundary area is higher than in the center of the upper weld. Consequently, the $M_{S}$ is lower here. This in turn means that the phase transformation at $0.1 \mathrm{~mm}$ starts later than at $0.2 \mathrm{~mm}$. At $0.2 \mathrm{~mm}$, the martensite formation already starts, while in $0.1 \mathrm{~mm}$ the transformation is delayed. As a result, residual compressive stresses are built up at a later time, while the phase transformation has already started in the core of the upper weld. Consequently, it may explain why the compressive stresses are higher at $0.1 \mathrm{~mm}$ depth than at $0.2 \mathrm{~mm}$ depth.

\section{Conclusion}

In this work, a high alloy base material (1.4301/304) was electron beam welded with a similar filler wire (G19 9/308L) and a dissimilar filler wire (G3Si1/70S-6). The aim was to induce the LTT effect by combining different materials in situ.

1 In an austenitic steel, a martensitic structure can be created in the weld seam by using a low alloy filler wire. Without any oscillation, two zones with different microstructures are created; a martensitic microstructure in the upper area of the weld seam and an austenitic microstructure in the bottom part. Neither solidification cracks nor retained austenite occur.

2 Due to the created martensitic structure in the upper area of the weld seam, an increase in hardness occurs. However, the hardness in the bottom part of similar and dissimilar welds do not increase.

3 With the distribution of low alloy filler wire in high alloy base material the $\mathrm{Cr}$ and $\mathrm{Ni}$ content within a weld seam can be reduced. However, the element distribution is not homogeneous, which leads to an inhomogeneous distribution of the martensitic transformation temperature. Nonetheless, a reduced $M_{S}$ is the result.

4 A LTT structure in the upper part of the weld seam has a positive effect on the distortion of a welded specimen. With the delayed formation of martensite, the thermal expansion in the upper part is greater than in the bottom part. With a similar weld a distortion of the sample is caused, whereby with the LTT effect, caused by the dissimilar weld in the upper part of the weld, the sample bents in negative direction. In order to obtain a precise setting of the distortion compensation, it must also be investigated how much material or volume of LTT has to be fed into the weld seam.

5 Due to the reduced transformation temperature of martensite within the weld seam, longitudinal compressive stresses build up. This does also affect the residual stresses in the close vicinity of the weld seam. The effect decreases, however, with greater distance to the weld seam, where residual stresses are a result of inhomogeneous thermal distribution only.

Acknowledgments Open Access funding enabled and organized by Projekt DEAL. The presented investigations were carried out at RWTH Aachen University Welding and Joining Institute ISF within the framework of the Collaborative Research Centre SFB1120-236616214 "Bauteilpräzision durch Beherrschung von Schmelze und Erstarrung in Produktionsprozessen." The sponsorship and support is gratefully acknowledged.

Funding This study is funded by the Deutsche Forschungsgemeinschaft e.V. (DFG, German Research Foundation).

Open Access This article is licensed under a Creative Commons Attribution 4.0 International License, which permits use, sharing, adaptation, distribution and reproduction in any medium or format, as long as you give appropriate credit to the original author(s) and the source, provide a link to the Creative Commons licence, and indicate if changes were made. The images or other third party material in this article are included in the article's Creative Commons licence, unless indicated otherwise in a credit line to the material. If material is not included in the article's Creative Commons licence and your intended use is not permitted by statutory regulation or exceeds the permitted use, you will need to obtain permission directly from the copyright holder. To view a copy of this licence, visit http://creativecommons.org/licenses/by/4.0/.

\section{References}

1. Lippold JC (2015) Welding metallurgy and weldability. John Wiley \& sons Inc, Hoboken, New Jersey

2. Simoneau R, Thibault D, Fihey J-L (2009) A comparison of residual stress in Hammer-Peened, Multi-Pass Steel Welds-A514 (S690Q) and S41500. Weld World 53:R124-R134. https://doi. org/10.1007/BF03266717

3. Radaj D (2012) Heat effects of welding: temperature field, residual stress, distortion. Springer Science \& Business Media 
4. Kromm A, Böllinghaus T (2011) Umwandlungsverhalten und Eigenspannungen beim Schweißen neuartiger LTTZusatzwerkstoffe. Zugl.: Magdeburg, Univ., Fak. für Maschinenbau, Diss., 2011. BAM-Dissertationsreihe, vol 72. Bundesanstalt für Materialforschung und -prüfung (BAM), Berlin

5. Zerbst U (2020) Application of fracture mechanics to welds with crack origin at the weld toe - a review. Part 2: welding residual stresses. Residual and total life assessment. Weld World 64:151169. https://doi.org/10.1007/s40194-019-00816-y

6. Withers PJ, Bhadeshia HKDH (2001) Residual stress. Part 1 measurement techniques. Mater Sci Technol 17:355-365. https:// doi.org/10.1179/026708301101509980

7. Heeschen J, Nitschke T, Theiner WA et al (1988) Schweißeigenspannungen - Grundlagen, Bedeutung und Auswirkung in geschweißten Bauwerken: Schweißen und Schneiden '88. DVS-Berichte, vol. DVS-Verl., Düsseldorf, p 112

8. Nitschke-Pagel T, Wohlfahrt H (2002) Residual Stresses in Welded Joints - Sources and Consequences. MSF 404-407: 215-226. https://doi.org/10.4028/www.scientific.net/MSF.404-407.215

9. Schulze G (2010) Die Metallurgie des Schweissens: Eisenwerkstoffe - nichteisenmetallische Werkstoffe, 4., neu bearbeitete Aufl. VDI-Buch. In: Springer. Heidelberg, New York

10. Bühler H, Scheil E (1933) Zusammenwirken von Wärme- und Umwandlungsspannungen in abgeschreckten Stählen. Archiv für das Eisenhüttenwesen 6:283-288. https://doi.org/10.1002/srin. 193300417

11. Jones WKC, Alberry PJ (1977) A model for stress accumulation in steels during welding. Residual stresses in welded construction and theri effects, International Conference

12. Kromm A, Dixneit J, Kannengiesser T (2014) Residual stress engineering by low transformation temperature alloys - state of the art and recent developments. Weld World 58:729-741. https://doi.org/ 10.1007/s40194-014-0155-6

13. Bhadeshia HKDH (2004) Developments in martensitic and bainitic steels: role of the shape deformation. Mater Sci Eng A 378:34-39. https://doi.org/10.1016/j.msea.2003.10.328

14. Leblond JB, Mottet G, Devaux JC (1986) A theoretical and numerical approach to the plastic behaviour of steels during phase transformations-I. Derivation of general relations. Journal of the Mechanics and Physics of Solids 34:395-409. https://doi.org/10. 1016/0022-5096(86)90009-8

15. Martinez Díez F (2008) Development of a compressive residual stress field around a weld toe by means of phase transformations. Weld World 52:63-78. https://doi.org/10.1007/BF03266655

16. Francis JA, Stone HJ, Kundu S et al (2008) Transformation temperatures and welding residual stresses in ferritic steels. In: Lidbury D (ed) Proceedings of the ASME Pressure Vessels and Piping Conference - 2007: Presented at 2007 ASME Pressure Vessels and Piping Conference, July 22 - 26, 2007, San Antonio, Texas, USA. ASME, New York, NY, pp 949-956

17. Ohta A, Watanabe O, Matsuoka K et al (1999) Fatigue strength improvement by using newly developed low transformation temperature welding material. Weld World 43:38-42

18. Shiga C, Yasuda HY, Hiraoka K et al (2010) Effect of $M_{s}$ temperature on residual stress in welded joints of high-strength steels. Weld World 54:R71-R79. https://doi.org/10.1007/BF03263490

19. Francis JA, Stone HJ, Kundu S et al (2009) The effects of filler metal transformation temperature on residual stresses in a high strength steel weld. J Press Vessel Technol 131. https://doi.org/10. $1115 / 1.3122036$

20. Stone HJ, Bhadeshia HKDH, Withers PJ (2008) In Situ Monitoring of Weld Transformations to Control Weld Residual Stresses. MSF 571-572: 393-398. https://doi.org/10.4028/www.scientific.net/ MSF.571-572.393

21. Dai H, Francis JA, Stone HJ et al (2008) Characterizing phase transformations and their effects on ferritic weld residual stresses with X-rays and neutrons. Metall Mat Trans A 39:3070-3078. https://doi.org/10.1007/s11661-008-9616-0

22. Bhadeshia HKDH, Francis JA, Stone HJ et al (2007) Transformation plasticity in steel weld metals. Shaker

23. Ramjaun TI, Stone HJ, Karlsson L et al (2014) Surface residual stresses in multipass welds produced using low transformation temperature filler alloys. Sci Technol Weld Join 19:623-630. https:// doi.org/10.1179/1362171814Y.0000000234

24. Dai H, Moat RJ, Withers PJ (2012) Modelling the interpass temperature effect on residual stress in low transformation temperature stainless steel welds. In: Duncan AJ (ed) Proceedings of the ASME Pressure Vessels and Piping Conference - 2011: Presented at ASME 2011 Pressure Vessels and Piping Conference, July 17 21, 2011, Baltimore, Maryland, USA. ASME, New York, NY, pp $1451-1458$

25. Ohta A, Suzuki N, Maeda Y et al (2003) Fatigue strength improvement of lap welded joints by low transformation temperature welding wire - superior improvement with strength of steel. Weld World 47:38-43. https://doi.org/10.1007/BF03266382

26. Francis JA, Gach S, Olscho S et al (2017) Characterisation of quasistationary temperature fields in laser welding by infrared thermography. Mat-wiss u Werkstofftech 48:1283-1289. https://doi.org/10. 1002/mawe.201700160

27. Gach S, Olschok S, Arntz D et al (2018) Residual stress reduction of laser beam welds by use of low-transformation-temperature (LTT) filler materials in carbon manganese steels - in situ diagnostic: image correlation. Journal of Laser Applications 30:32416. https://doi.org/10.2351/1.5040599

28. Andrews KW (1965) Empirical formulae for the calculation of some transformation temperatures. J Iron Steel Inst 203:721-727

29. Steven W, Haynes AG (1956) The temperature of formation of martensite and bainite in low alloy steels, some effects of chemical composition. J Iron Steel Inst 183:349-359

30. Grange R, Stewart HM (1946) The temperature range of martensite formation. Trans AIME 167:467-490

31. Rowland ES, Lyle SR (1946) The application of $M_{s}$ points to case depth measurement. Trans ASM 37:27-47

32. Carapella LA (1944) Computing A or MS (transformation temperature on quneching) from analysis. Met Prog 46:108

33. Payson P, Savage CH (1944) Martensite reactions in alloy steels. Trans ASM 33:261-280

34. Kung CY, Rayment JJ (1982) An examination of the validity of existing empirical formulae for the calculation of $M_{s}$ temperature. Metall Trans A 13:328-331. https://doi.org/10.1007/BF02643327

35. Eckstein HJ (1970) Wärmebehandlung von Stahl

36. Bargel H-J, Schulze G, Hilbrans H (2008) Werkstoffkunde, 10., bearb. Aufl. VDI-Buch. Springer-Verlag, Berlin, Heidelberg

Publisher's note Springer Nature remains neutral with regard to jurisdictional claims in published maps and institutional affiliations. 